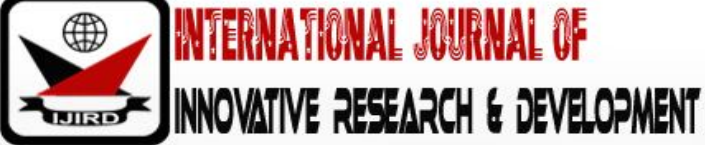

ISSN 2278 - 0211 (Online)

\section{Analyzing the Impact of Formal Education on Poverty Reduction among Rural Households in Northern Ghana: Evidence from the Jirapa District, Ghana}

Alphonsus Beni
Senior Lecturer, Department of Philosophy and Social Sciences,
Spiritan University College, Ghana
Romanus Dinye
Professor, Department of Settlement Studies,
Alex Yao Segbafia
Kwame Nkrumah University of Science and Technology, Ghana
Senior Lecturer, Department of Geography and Rural Development,
Kwame Nkrumah University Science and Technology, Ghana
Prince Osei-Wusu Adjei
Senior Lecturer, Department of Geography and Rural Development,
Kwame Nkrumah University Science and Technology, Ghana
Lawrence Guodaar
Lecturer, Department of Education, Spiritan University College, Ghana

\begin{abstract}
Poverty is a global phenomenon affecting most people in the developing world including Northern Ghana. The study analysed the nexus between formal education and poverty reduction among rural households in the Jirapa district of Northern Ghana using a mixed-method case study design. A four stage multiple sampling strategy was employed to collect primary data from 701 household heads in the study communities using semi-structured interviews and focus group discussions. The data were analysed using quantitative (regression, chi-square, cross-tabulation, frequencies, percentages) and qualitative analytic tools (content analysis with direct quotations).The results revealed that formal education increases the chances of occupying modernized housing structure and also one's ability to meet his or her nutritional requirement. The relationship between formal education and poverty reduction (housing type, nutrition, monthly income, economic condition, financial dependency, job security, social exclusion, political exclusion) were statistically significant at the $1 \%, 5 \%$ and $10 \%$ probability levels. It is therefore imperative that education be made more accessible and possibly free to the Senior High level to enable households improve their livelihood opportunities.
\end{abstract}

Keywords: Formal education, poverty, regression analysis, Jirapa, Northern Ghana.

\section{Introduction}

Poverty is a global phenomenon affecting most people in the developing world, especially in Asia and Sub-saharan Africa. Even though several attempts were made by well-meaning international organizations such as the United Nations to alleviate poverty among vulnerable regions and developing economies, the phenomenon still remains a development agenda culminating in the introduction of the Sustainable Development Goals. Interestingly and imperatively, the SDG 1 is targeted at a complete eradication of poverty among poverty prone countries.

The role played by formal education in poverty reduction, in association with other social sector interventions, is critically essential. There is no country around the world that has developed if it has not educated its people. Education is not only essential in poverty reduction; it is also a key to wealth creation. Within this context, one of the pledges of the Dakar Framework for Action - Education for All (EFA):Meeting our Collective Commitments- was "to promote EFA policies within a sustainable and well-integrated sector framework strictly linked to poverty reduction and strategies for development" (United Nations International Children's Emergency Fund-UNICEF, 2000).

Masood et al. (2011), states that Education and poverty are inversely related. The higher the level of education of the population, the lesser will be the number of poor persons because education imparts knowledge and skills which is supportive in higher wages. The direct effect of education on poverty reduction is through increasing the income or wages. The indirect effect of education on poverty is important with respect to 'human poverty' because as education improves 
the income, the fulfillment of basic necessities becomes easier and raises the living standard which surely means a fall in human poverty.

Education indirectly helps in the achievement of basic essential needs such as shelter, water, health facilities, and sanitation. It also helps change the women's behaviour in fertility decisions and family planning (Jeffery \& Basu, 1996). It is understood that meeting such basic needs increases the productivity and wages consequently putting people above the poverty line. The linkages between education and poverty broadly can be seen in two ways: In the first instance, investment in education increases the skills and productivity of poor households and, therefore, increases the income level as well as the overall standard of living, that is, human development. Secondly, poverty is also a serious hindrance to educational achievement.

Poverty has a negative influence on the educational attainment in three ways. The first comes from lack of resources, that is, financial resources. The second comes from the creation of social pressures which destroys the mindset of a poor student. The third is that, when poverty affects any institution it decreases the standard of teaching and learning (Branley \& Karley, 2005). At the international level, it can generally be identified that countries that are considered poor have low levels of education and at the national level children who do not attend schools, comes from poor families. In Pakistan for example, it is estimated that $80 \%$ of the 6.5 million children who are not in school have never even enrolled in any school at all (UNESCO, 2007). The main reasons why children are not in schools are both economic and non-economic challenges. For example, male children are considered as source of income in the form of child labour, that is, they are used either in the farm or trading in the market for their parents; girls are considered very helpful to their mothers in household work and in taking care of their younger sisters and brothers.

In addition to that, there are some social norms and religious doctrine which hinder the education of the girl child. Consequently, lack of education becomes the cause of low earning potential of any person and family and poverty persists even to the next generations of that household. Pakistan is considered to be among the second of the world countries with the highest number of children who are out of school, and it is because of extreme poverty affecting more than 60 percent of the population that lives on $\$ 2$ a day. It can be understood that 'education poverty' and 'income poverty' have a mutually reinforcing relationship with each other both at the macro and micro levels. Lack of education is a key factor of income poverty and absence of sufficient income cannot overcome the education poverty either (Tilak, 2005).

As indicated earlier on, education plays an important role in the fulfillment of basic needs, through poverty reduction and these basic needs include the availability of education itself, in other words provision of education and fulfillment of basic needs both reinforce each other (UNESCO - PROAP, 1998). Also, as stated earlier on, the inverse relationship between education and poverty has been well noticed but there is a debate relating to the educational levels; whether primary education is enough for the ultimate outcomes or all educational levels (Primary, Junior High, Senior High and Tertiary education) have to be focused simultaneously. The main focus of the Millennium Development Goals (MDGs) of the United Nations on education and the Poverty Reduction Strategy Papers (PRSP) approved by the World Bank put more emphasis on primary education and girls' education (Tilak, 2005).

In the less developed countries the social returns of primary education are much higher as compared to that of tertiary education and most of the time the relatively rich people continue their tertiary education, expanding tertiary education is estimated to be twenty to fifty times expensive as compared to the primary education expansion (Colclough, et al. 2003). It is therefore not surprising that, developing countries want to reduce poverty in the cheapest manner possible and that's why primary education is given the most priority (Colclough, et al. 2003).

The Northern regions continue to present Ghana with the most formidable developmental challenge. Of the five regions (Northern, Upper East, Upper West, Central and Eastern Regions) in Ghana with the highest levels of poverty in 1992, three are in northern Ghana. While other regions have seen poverty levels decline dramatically over the past one and half decade Northern Ghana has fallen further behind. There has been an erratic trend in poverty levels in Northern Ghana compared with the rest of Ghana. In this respect, Northern Ghana stands in sharp contrast with the rest of the country, especially the Central and Eastern Region, where poverty is being reduced consistently across the regions and over time. In Ghana, poverty is disproportionally concentrated in the North. The Northern part of Ghana has benefited very little from poverty reduction which took place at the national level (GSS, 2000). In terms of extreme poverty incidence, apart from the three northern regions, whose rates are higher than the national rate of extreme poverty, all the other regions in the coastal and forest areas have rates lower than the national average. Upper West Region has the highest extreme poverty incidence of 45.1 percent, followed by Northern (22.8\%) and Upper East (21.3\%) (GSS, 2014).

A greater number of households in the three northern regions appear to be in a situation of chronic and persistent poverty mainly due to lack of formal education and isolation from markets. There are significant disparities in household access to education and health care. Households in these regions have remained disconnected from economic growth taking place in the rest of the country, with limited opportunities to escape from poverty because of their limited access to education, health care, market and other public services (World Bank, 2016).

It is argued that the distribution of poverty incidence and poverty gap vary by the level of education of the household head. According to the Ghana Statistical Service (2014), poverty is higher among households whose heads are uneducated than among those with some education. The report further suggests that the level of poverty reduces as the educational level of the household head increases. More than a third of household heads with no education are poor compared with 15.7 percent of those with a BECE and 8 percent of those with a secondary education. Only three percent of heads with a tertiary education are poor. The contribution to national poverty incidence by households headed by an uneducated person is 72.4 percent, whilst the highly educated accounts for less than one percent. The report concludes that a strong negative relationship exists between poverty and educational level, such that the more educated the household head is the less likely they are to be poor (GSS, 2014). It is in the light of this that this study wants to further 
explore and add to the literature the situation in the Jirapa districts in Northern Ghana where the incidence of poverty is very high with its concomitant variations in the levels of education of the households. The study hypothesizes that formal education has no impact on poverty reduction.

\section{Materials and methods}

\subsection{Study Area}

The District is one of the 11 districts in the Upper West Region with the administrative capital being Jirapa. The Jirapa District is located in the North Western corner of the Upper West Region of Ghana and shares boundaries with Lambussie District to the North; Lawra District to the West; Nadowli District to the Southand Daffiama-Bussie-Issa District to the East (See Fig. 1). According to the 2010 National Population Census, the Population of the Jirapa District stood at 88,402 distributed across all ages and different sexes. This numbercomprises 53.0 percent females and 47.0 percent males. Relatively, the Jirapa District is the fourth largest in area and second in terms of the size of the population. The district has a population size of 88,402 and a total land area of 1,667.6 square kilometers, with the population density being 58.1 persons per square kilometer. This figure is almost double the regional density of 31.2. Therefore, it means that there is emerging pressure on land and other resources. About $5 \%$ of the people live in major towns of the District while a significant 95\% live in rural settlements. The major tribes are the Dagaabas and Sissala.The dominant economic activity in the district is agriculture with $80 \%$ of them being predominantly peasant farmers. The major crops are millet, maize, sorghum, cotton and groundnuts. Livestock farming is practiced throughout the district (GSS, 2012).

The Jirapa District is found within the tropical continental climatic zone with mean-annual temperature ranging between 28 degrees Celsius to 31 degrees Celsius. The district experiences a single rainy season which starts in June and ends in October, giving way to a long dry season from November to May. There is also variability in rainfall pattern year to year, resulting sometimes in intermittent droughts and floods. Generally, the annual rainfall ranges between 900 $1,100 \mathrm{~mm}$ (Jirapa District Website).

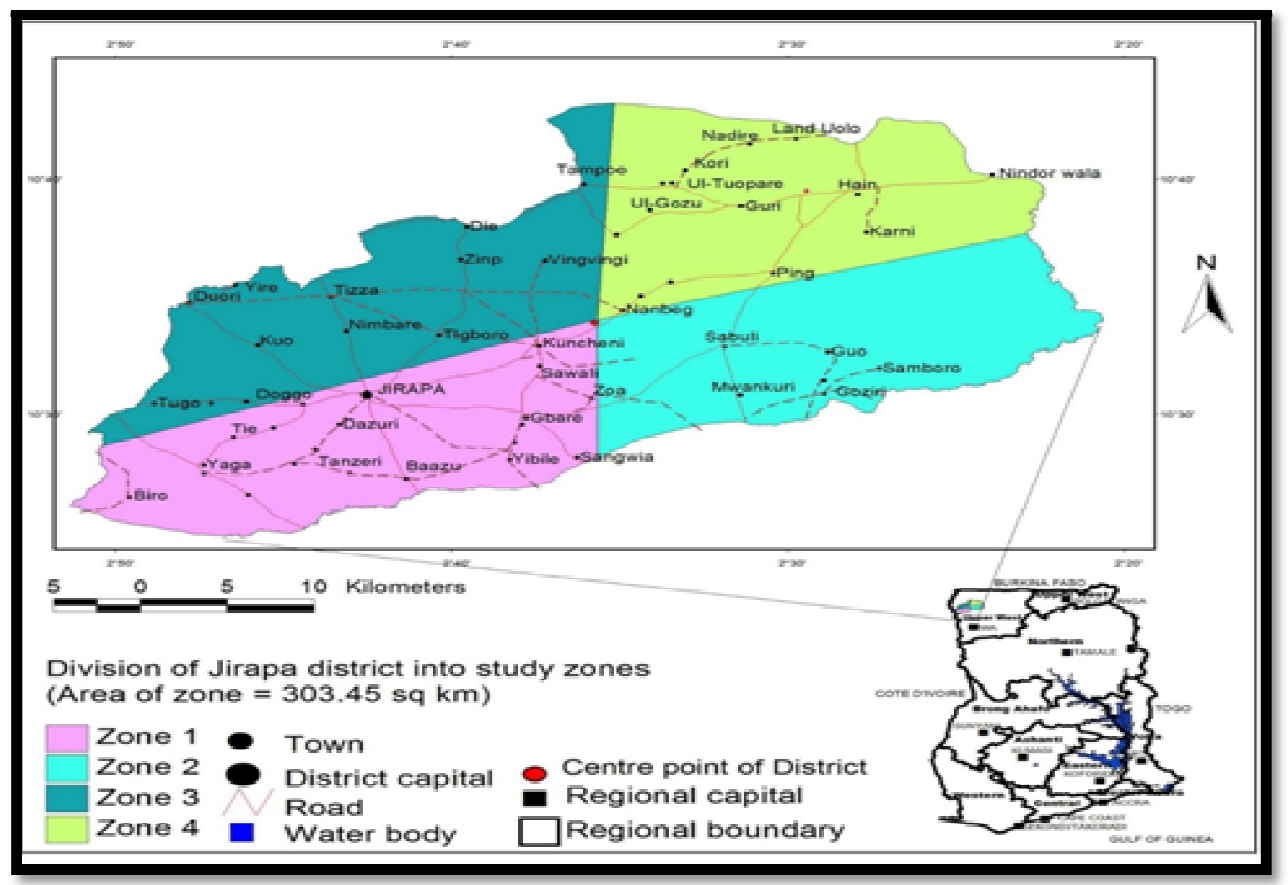

Figure 1: Map of Selected Communities in the Jirapa District Source: Geographic Information System Coordinates

\subsection{Research Approach}

The study utilized the mixed method triangulation approach for the data collection and analyses. Mixing the methods was deemed appropriate because the qualitative responses reinforced the quantitative responses for a holistic solution to the research problem under investigation (Creswell, 2010).

\subsection{Research Design}

The case study design was employed for the study. The case study is a research approach that is employed to provide an in-depth understanding of a complex issue under investigation in its real-life context (Yin, 2009). It is an established research design that is extensively used among scientific research disciplines, especially the social sciences. This design is relevant in providing an opportunity to understand and explain causal relationships between and among variables (Yin, 2009). Case study may be approached in different ways depending on the epistemological perspective and orientation of the researcher: it may take an interpretivist approach (qualitative), positivist approach (quantitative) or pragmatist approach (mixed) (Brazier et al., 2008). This particular study employed, used the case study in a mixed method design for the data collection and analysis. The case study design also provide an opportunity to collect data from several 
sources using varieties of quantitative and qualitative data collection tools to increase internal validity of a study (Stake, 1995).

\subsection{Sample Technique}

A four stage multiple sampling strategy was employed for the study. The first stage involved the use of stratified sampling technique to put the district into two main strata namely; rural and urban. The second stage involved the use of purposive sampling with the help of expert advice in selecting the study communities in the Jirapa District. The third stage involved the stratification of the study communities into four zones to ensure equal representation of the study communities. The stratification of the communities into zones was to ensure the representation of all the various communities with varied poverty levels. The fourth and final stage involved the use of simple random sampling strategy in selecting household heads from the four stratified zones of the communities. The table of random digits, facilitated by computer software was employed as strategies for the simple random sampling. This technique allowed the researcher to determine desired levels of sampling precision for each group in a zone, and provided administrative efficiency. The main advantage of the approach is that it is able to give the most representative sample of a population (Hunt \& Tyrrell, 2001). The household sampled constitute the sampling units. The sampling in this technique is mainly geographically driven. The sampling frame is also often readily available for each category (urban or rural).

\section{5: Sample Size}

The entire Jirapa District was divided into four zones using GIS which were made up of 12400 households; this is divided into two household areas. Urban households are 2,400 and rural households are 10,000. Krejcie and Morgan (1970) recommended a sample size of 701 for a population of 12400 at $5 \%$ margin of error with $95 \%$ degree of confidence. This is made up of a proportionate sample size of 136 for urban population of 2400, and a sample size of 565 for a rural population of 10,000 (Appendix A). The mathematical model used for the proportionate sample sizes was: HP/THP * TSS where HP is the household population; THP is the total household population and TSS being the total sample size. The division of the entire Jirapa District into zones and further divided into urban and rural households was to ensure that different geographical locations in the District were given equal chance of selection for data collection. It was to ensure representation of communities from different segments of the District for data collection.

In addition to the heads of household from whom data was elicited, twenty more respondents were randomly selected from each zone, ten from among each cluster for focus group discussion to compare differences in poverty conditions between urban households and rural households of the study area. The 136 respondents from the urban areas include heads of household with relatively higher level of education, higher income, urban culture which includes, good housing condition, means of transport and access to health care facilities, to help properly assess how differences in educational levels, socio-cultural and geographical variations could affect poverty. Due to the homogenous nature of the rural communities and that of the urban communities in terms of their socio-economic, socio-cultural and demographic characteristics, the sample size of 701 households was found to be appropriate for a thorough investigation into the problem in the study area.

\subsection{Data Collection Instruments and Methods}

Both primary and secondary sources of data were used for the research. The primary information was elicited from selected respondents living in both the rural and urban areas about their education, access to job opportunities, health care, and their poverty status in terms of income, housing etc. Data from education officers and practitioners directly involved in the provision of educational facilities for both the urban and rural communities were collated for analysis. Other education and poverty related documents were also consulted for information to put the problem in its right perspective.

Semi-Structured interview guide, focus group discussion guide and participant observation were the instruments for data collection. Respondents were visited in their houses in the study areas for adequate and relevant data. In each case, questions were semi-structured and read out to respondents in their own local dialect for clarity and understanding of questions. This was necessary to ensure that the data collection process was interactive and participatory, and that respondents understood well the questions to which they were to respond. This was because majority of the people within the target group had no formal education; hence, a direct and face to face interaction with them was to make the data collection more efficient and reliable.

The focus group discussions were conducted to supplement data obtained with the semi-structured interview. The discussions involved both male and female heads of household to unveil their perception of education and how its effect on poverty in the study area. Focus group discussions of twenty members, with ten members each from the urban and rural clusters was randomly selected to conduct the survey for heads of household in the study communities. The cultural dimension and its effects on poverty reduction of the study area were captured in the focus groups discussions. The rationale was to examine the perception of poverty based on which appropriate strategies could be developed. These methods helped to understand formal education from the rural and urban area setting and its effects on poverty reduction.

\subsection{Data Analysis}

The data were analysed using both qualitative and quantitative analytic tools. The quantitative data were analysed using both descriptive and inferential statistics. The descriptive statistical tools employed for the study include frequencies and percentages, cross-tabulations and chi-squares. These were presented in the form of tables, graphs and charts for easy identification and quick visual impression. Inferentially, simple linear regression as well as multivariate 
binary logistic regression was also used to show the relationship between some explanatory and response variables. The regression analysis was also used to test the hypotheses of the study. The IBM Statistical Package for Social Sciences (SPSS software) version 22 was a suitable tool for the analysis of the quantitative data elicited from the primary respondents (household heads). The SPSS software was appropriate because it is a statistical software package that is capable of organizing and analyzing quantifiable data as well as cross- tabulating the relationship between variables. Before the data were analysed, they were carefully cleaned to do away with some errors associated with the entry. Such corrections were possible because of the numbers assigned to each of the questionnaires used for the data collection.

The qualitative data were analysed using content analysis. The qualitative data collected from the focus group discussion were recorded using a tape recorder and later transcribed into text. The transcribed text was later analysed based on the content of the responses provided by the respondents during the focus group discussion. The analyses of the content of the data were possible through the grouping of the responses into sections with each section focusing on a particular objective. The sections were used as broad themes that emerged from the focus group discussion. Direct quotations of some discussants were used to buttress the quantitative responses. For ethical consideration, the names of quotations of the respondents were not used in order to preserve the anonymity of their identity.

\section{Results and Discussion}

\subsection{Socio-Economic Characteristics of Respondents}

\subsubsection{Age-Sex Distribution of Respondents}

From Table1, it is evident that most of the respondents are males (605) constituting $86.4 \%$ of the respondents and females constitutes minority of the respondents (95) constituting $13.6 \%$ of the respondents. This is understandably so since the study area practices the patrilineal system of inheritance in which the household head is a male in most cases. It is therefore a male dominated household heads society (Table 1).

\begin{tabular}{|c|c|c|c|c|c|c|}
\hline Age & \multicolumn{3}{|c|}{ Sex } & \multicolumn{2}{c|}{ Totals } \\
\hline & \multicolumn{2}{|c|}{ Male } & \multicolumn{2}{c|}{ Females } & & \\
\hline & Frequency & Percentage & Frequency & Percentage & Frequency & Percentage \\
\hline 20 & 2 & 0.3 & 6 & 6.3 & 8 & 1.1 \\
$20-29$ & 154 & 25.5 & 23 & 24.2 & 177 & 25.3 \\
\hline $30-39$ & 194 & 32.1 & 24 & 25.3 & 218 & 31.1 \\
\hline $40-49$ & 120 & 19.8 & 18 & 18.9 & 138 & 19.7 \\
\hline $50-59$ & 73 & 12.0 & 15 & 15.8 & 88 & 12.6 \\
\hline $60-69$ & 42 & 6.9 & 8 & 8.4 & 50 & 7.1 \\
$70-79$ & 11 & 1.8 & 1 & 1.1 & 12 & 1.7 \\
$>80$ & 9 & 1.5 & 0 & 0 & 9 & 1.3 \\
\hline Total & 605 & $100 \%$ & 95 & $100 \%$ & 700 & $100 \%$ \\
\hline
\end{tabular}

Table 1: Age-Sex Distribution of Respondents

Source: Field Survey 2017

*Missing Value $=1$

It is also observed that, most of the respondents (28\%) were in the 30 -39 age group whiles the minority of the respondents (1.1\%) was in the less than 20 age group. However, respondents with age of less than 20 - 29 years were also made up of $25.3 \%$ whiles respondents with $40-49$ were also made up of $19.7 \%$ of the respondents. Respondents who are 60 - 69 years were also made up of $7.1 \%$ whiles $70-79$ also constituted $1.7 \%$.

The result indicates that the study area has more young population and less population at the age of 60 years upwards. This evident of the fact that a lot of people die before their $60^{\text {th }}$ birthday as a result of poverty that deprived them of the necessary nutrition, good and available health care system.

\subsubsection{Educational Level of Respondents}

The study revealed that most of the respondents had never schooled constituting $39.0 \%$, followed by those with tertiary level of education (36.0\%). Those who had secondary level of education also constituted $13.6 \%$ whiles those who had basic level of education also constitute $11.4 \%$ (Table 2).

\begin{tabular}{|c|c|c|}
\hline Educational Levels & Frequency (N) & Percent (\%) \\
\hline Basic & 80 & 11.4 \\
\hline Secondary & 95 & 13.6 \\
\hline Tertiary & 252 & 36.0 \\
\hline Never Schooled & 273 & 39.0 \\
\hline Total & 700 & 100 \\
\hline
\end{tabular}

Table 2: Educational Background of Respondents.

Source: Field Survey, 2017

$*$ Missing value $=1$ 


\subsubsection{Years of Schooling}

It was also recognized that majority of the respondents constituting $39.2 \%$ (270) have never been to school whiles 1.2\% (8) have been in school for 1 to 3 years. Out of these 700 household heads 39.2\% (272) have never been to school, thus have no years of schooling whiles $6.5 \%$ (45) have 4 to 6 years of schooling. It was further realized that $4.2 \%$ (29) have 7 to 9 years of schooling whiles $10.7 \%$ (74) have schooled for 10 to 12 years. 162 also representing $23.3 \%$ have also been to school for 13 to 15 years, whiles 104 representing $15 \%$ have also schooled for more than 15 years (Table 3).

\begin{tabular}{|c|c|c|}
\hline Years of Schooling & Frequency (N) & Percent (\%) \\
\hline 0 & 272 & 39.2 \\
\hline $1-3$ & 8 & 1.2 \\
\hline $4-6$ & 45 & 6.5 \\
\hline $7-9$ & 29 & 4.2 \\
\hline $10-12$ & 74 & 10.7 \\
\hline $13-15$ & 162 & 23.3 \\
\hline$>15$ & 104 & 15.0 \\
\hline Total & 700 & 100 \\
\hline
\end{tabular}

Table 3: Years of Schooling

Source: Field Survey, 2017

$*$ Missing value $=1$

\subsection{The Impact of Formal Education on Poverty Reduction}

\subsubsection{Effect of Formal Education on Type Dwelling Unit}

This section presents and interprets the empirical results on the effect of formal education on house type. The results are presented in Table 4 .

\begin{tabular}{|c|c|c|c|c|c|}
\hline Variable & Coefficient & Standard Error & Wald-Statistic & $\begin{array}{c}\text { Marginal } \\
\text { Probability }\end{array}$ & P-value \\
\hline Basic & -.117 & .364 & .103 & .890 & .749 \\
\hline Secondary & $.713^{*}$ & .402 & 3.142 & 2.039 & .076 \\
\hline Tertiary & $1.077^{* * *}$ & .332 & 10.505 & 2.937 & .001 \\
\hline Income & $.005^{* *}$ & .003 & 4.048 & 1.005 & .044 \\
\hline Livestock & $.748^{* *}$ & .334 & 4.999 & 2.112 & .025 \\
\hline Household Size & -.047 & .037 & 1.582 & .954 & .209 \\
\hline Crop Farm & .272 & .404 & .452 & .501 & 1.312 \\
\hline
\end{tabular}

Table 4: Effect of Formal Education on Type of Dwelling Unit

*Denotes Statistical Significance at the 10 Percent Level, **Denotes Statistical

Significance at the 5 Percent Level and ***Denotes Statistical Significance at The 1 Percent Level

Source: Author's Construction Based On Data Obtained From the Field of Study

The results revealed statistical insignificant difference in the probability of occupying more modernized housing type ( detached, semi-detached and flat) between the non-educated without income-generating asset and those with basic education regardless of income, household size and asset holding ( ownership of livestock and crop farm) even at the 10 percent level of significance. In other words respondents with basic education have equal chance of occupying more modernized house type with non-educated. This is intuitively plausible since individuals educated to the basic level earn merger amount of income thus serving as a constraint to occupy more modernized housing structure. In fact the noneducated learn trade early so that they are able to migrate to the level of individuals with basic education in terms of income levels and other livelihood conditions. Thus, one will observe that there are negligible differences in living conditions especially with respect to the housing structure they occupy.

Another revelation of the results indicates that there is a quite significant difference between secondary schools leavers and the non-educated at the 10 percent level of significance everything being equal. The secondary school leavers are more likely to occupy more modernised house type relative to the non-educated given their household size, income, and asset holding. The odd in favour of occupying more modernized house type is more than twice relative to the noneducated.This result is intuitively correct. Those who are educated to the secondary level migrate on the social ladder or upgrade their social convoy with their occupation, income levels, friends association thus to "keep up with the jones" they must improve their living conditions by occupying a more modernized housing structure. In terms of the odds of occupying more modernised structure, the secondary school leavers are doing more than twice better than the noneducated. Thus, the gap between secondary leavers and the non-educated is quite substantial giving credence to relevance education in improving livelihood of the people in district, the country, Africa and the world at large.

Further to these results, there is highly significant difference between tertiary portfolio respondents and the noneducated at the l percent level of significance. Tertiary portfolio respondents are more likely to occupy more modernized house type relative to the non-educated, ceteris paribus. An odd for tertiary portfolio respondents is 3 more times than the non-educated with zero income-generating asset holding. There is wide gap between the tertiary educated and the non- 
educated in terms of livelihood all things being equal. The tertiary educated are able to rise up quickly in the social ladder. They have access to better jobs, better levels of income, better association and links and to mention a few. Thus, they have more chance to enjoy better living condition relative to the non-educated counterpart who are mostly farmers or traders who earn low income due to primitive farming and poor price for their product and those who learn trade have to squeeze water out of stones to make ends meet. Thus, unable to afford to occupy more modernized housing structure. Not only that there is significant difference between the non-educated and tertiary educated but also the gap between is very wide. The odds ratio revealed that the tertiary educated individuals are 3 times better than the non-educated with respect to occupying modernized housing structure.

The empirical results also indicate that income of the respondents exert significant effect on the probability of owning non-traditional housing structure at the 5 percent level of significance. The higher the income level of respondents, the more likely for the people to occupy more modernized house type given their educational level, the size household, and income-generating asset holding. The odds in favour of occupying more modernized house type 1 as income increases by GHS1. One of the key determinants of demand for goods and services is income. It renders the individual the purchasing power to command goods and services. Hence, all things being equal, the higher the income level the higher the demand for goods and services. Economic theory recognizes that not all goods and services that will respond positively to increases in income levels of the consumer. Those that respond positively are termed as normal goods whiles negative effects are termed as inferior goods. Thus, judging from the empirical results, one can conclude modernized house type is a normal good in the surveyed district.

The results further indicates significant difference in the probability of occupying more modernized housing structure between the respondents who own livestock and the reference group at the 5 percent level of significance. The respondents who own livestock are more likely to occupy more modernized housing structure relative to the noneducated with no income-generating assets. The odd in favour of occupying modernized housing structure is 2 times higher than the non-educated without income generating assets. Assets is one of the determinants of consumption of goods and services. Owning assets gives the individual the space to spend on luxurious product such automobiles, patronage of airline, owning and occupying more modernized house and to mention a few. Thus, like income, owning an asset especially income-generating assets improve your purchase power and being able to afford normal and luxurious goods and services.

\subsubsection{Regularity of Household Monthly Income and Formal Education}

This section discusses the relationship between household monthly income and formal education. It further disaggregates formal education into basic, secondary and tertiary and how these levels of formal education related to the incidence of regularity of household monthly income compared with the uneducated.

The results reveal a Chi-square value of 104.024 with the probability value of 0.000 . This gives the indication that there is a significant relationship between one's educational status and regularity of household monthly income at the 1 percent level of significance. In other words, the regularity of monthly income is dependent once educational status. The results are presented in Table 5.

\begin{tabular}{|c|c|c|c|}
\hline \multirow{2}{*}{ Educational Status } & \multicolumn{3}{|c|}{ Regularity of Household Monthly Income } \\
\cline { 2 - 4 } & Regular & Not Regular & Total \\
\hline Non-Educated & 83 & 172 & 255 \\
& $32.5 \%$ & $67.5 \%$ & $100 \%$ \\
\hline Educated & 246 & 162 & 409 \\
& $60.1 \%$ & $39.6 \%$ & $100 \%$ \\
\hline Chi-square Test & \multicolumn{3}{|c|}{$\chi^{2}=104.024 \quad \mathrm{P}=(.000)$} \\
\hline
\end{tabular}

Table 5: Relationship between Educational Status and Regularity of Household Monthly Income

Source: Author's Construction Based on Data Obtained from the Field of Study $*$ Missing Value $=37$

The results further reveal that out of total number of 255 respondents who are uneducated, 172 of them representing 67.5 which represent the majority indicated that their monthly income are irregular. The remaining $32.5 \%$ of them indicated that their monthly incomes are regular. Thus, the probability of non-educated being vulnerable in the context of irregular source of monthly income is 68 percent. The total number of educated is 409.246 of the educated indicated that their monthly income is regular representing $60.1 \%$ which forms the majority. The minority of them representing $39.6 \%$ indicated that their monthly income is not regular. Hence, the probability of educated being vulnerable in the context of irregular source of monthly income is $39.6 \%$. Thus, the study concludes that respondents with formal education are less likely to be vulnerable relative to the uneducated in the context of regularity of monthly income. Individuals with formal educational have the skills and credentials that enable them to secure jobs that turn gives them maximum security such as regular source of income. They are employed in government institutions which gives them high levels of job security, and regular source of income. Some are also employed in private sector such as the manufacturing companies as floor managers, general managers and financial institutions such as banking institutions, insurance companies and research institutions, N.G.Os and to mention but a few. Besides being employed in the formal sector which gives them regular source of income, they are also financially literate and have better information on investment ventures such as investment in securities like bonds and treasury bills as well as investment in the stock market. 


\section{Economic Condition and Formal Education}

This sub-section discusses the relationship between the respondents' economic condition and formal education. The results are presented in Table 5.4.

\begin{tabular}{|c|c|c|c|c|c|c|}
\hline Educational Status & \multicolumn{7}{|c|}{ Economic Condition } \\
\hline & Much worse & Worse & Same & Better & Much better & Total \\
\hline Non-educated & 16 & 95 & 87 & 47 & 3 & 249 \\
& $6.4 \%$ & $38.2 \%$ & $34.9 \%$ & $18.9 \%$ & $1.2 \%$ & $100 \%$ \\
\hline Educated & 17 & 128 & 122 & 111 & 9 & 387 \\
& $4.4 \%$ & $33.1 \%$ & $31.5 \%$ & $28.7 \%$ & $2.3 \%$ & $100 \%$ \\
\hline Chi-square Test & $11.848(0.037)$ & \multicolumn{7}{|l|}{} & & & & \\
\hline
\end{tabular}

Table 6: Economic Condition and Formal Education

$*$ Missing Value $=64$

Source: Author's Construction Based on Data Obtained from the Field of Study, 2016

The Chi-square revealed that there is significant relationship between economic condition and educational status of the respondents at the 1 percent level of significance, $\chi^{2}(636,4)=11.848, p=.037$. That is economic condition varies across the educational background of the respondents. The results revealed that 16 of the non-educated representing 6.4 percent indicated that their economic condition is much worse relative to previous year's economic condition. Majority of the respondents of the non-educated representing 38.2 percent indicated that their economic condition were worse relative to the previous year. Total number of $87,47,3$ representing $34.9 \%, 18.9 \%$ and $1.2 \%$ percent respectively indicated that their economic conditions are the same, better and much better respectively. On the aggregate, the probability of being worse off for non-educated is 44.2 percent (6.4 percent plus 38.2 percent). The total number of the educated respondents was 387. Out of this number, 17 of them indicated that their economic conditions are much worse representing 4.4 percent which is lower than the uneducated. Again, 128 of them indicated that their economic condition is worse representing 33.1 percent. 31.5 percent, 28.7 percent and 2.3 percent indicated that their economic conditions are the same, better and much better respectively. Thus, the probability of being worse off for the educated is 37.5 percent (4.4 percent plus 33.1 percent) which is statistically smaller than the uneducated. Thus, the educated are less likely to be vulnerable in terms of economic condition relative to the non-educated. This was highlighted in the focus group discussion in Ul-Dantie when a contributor, in his submission indicated remarked: look around and see those in good cloths are mostly the educated people but the uneducated are those without good cloths, without good housing, without good food, without good health care and without good sanitary facilities as compared with the educated (FGD, 2016).

A good observation of the study communities shows a clear disparity between the educated and the uneducated. Government efforts to reduce regional imbalances must be supplemented by local action (Bening, 1990). The chronic and persistent poverty in the northern Regions of Ghana is attributable to the geography and poverty traps as a result of low school enrollment and other variables in development. GSS (2014) data reveal that, the key area that continues to worsen and is a clear source of concern is that of equity. Ghana's inequality measure, the Gini Coefficient, has risen from 41.9 in 2005/ 06 to 42.3 in 2012/13, an indication that increasingly, income is shared inequitably across the population. This is particularly so in the Jirapa District. This level of inequality has adverse implications towards Government's efforts at reducing poverty in the country.

\begin{tabular}{|c|c|c|c|c|c|c|}
\hline Educational Status & \multicolumn{7}{|c|}{ Economic Condition } \\
\hline & Much worse & Worse & Same & Better & Much better & Total \\
\hline Non-educated & 16 & 95 & 87 & 47 & 3 & 249 \\
& $6.4 \%$ & $38.2 \%$ & $34.9 \%$ & $18.9 \%$ & $1.2 \%$ & $100 \%$ \\
\hline Basic & 4 & 31 & 24 & 17 & 1 & 77 \\
& $5.2 \%$ & $40.3 \%$ & $31.2 \%$ & $22.1 \%$ & $1.3 \%$ & $100 \%$ \\
\hline Secondary & 8 & 33 & 19 & 19 & 1 & 80 \\
& $10 \%$ & $41.2 \%$ & $23.8 \%$ & $23.8 \%$ & $1.2 \%$ & $100 \%$ \\
\hline Tertiary & 5 & 64 & 79 & 75 & 7 & 230 \\
& $2.2 \%$ & $27.8 \%$ & $34.3 \%$ & $32.6 \%$ & $3 \%$ & $100 \%$ \\
\hline Chi-square Test & 30.747 & & & & & \\
& $\mathrm{P}=.009$ & & & & & \\
\hline
\end{tabular}

Table 7: Economic Condition and Formal Education

$*$ Missing Value $=64$

Source: Author's Construction Based on Data Obtained from the Field of Study 2016

The results revealed a significant relationship between economic condition and each level of formal education, $\chi^{2}$ $(636,8)=30.747, p=009$. That is, economic condition varies across the educational background of the respondents. The results revealed that $(6.4 \%)$ of uneducated indicated that their economic condition was much worse relative to the previous year. Majority of the respondents of the non-educated representing 38.2 percent indicated that their economic condition were worse relative to the previous year. Nearly 35\%,19\% and 1\% indicated that their economic conditions are the same, better and much better, respectively. On the aggregate, the probability of being worse off for uneducated was 
$44.2 \%$. The total number of the educated respondents was 387. Again, 33.1\% of them indicated that their economic condition was worse while $31.5 \%, 28.7 \%$ and $2.3 \%$ indicated that their economic conditions are the same, better and much better, respectively. Thus, the probability of being worse off for the educated was $37.5 \%$ (4.4\% plus $33.1 \%$ ) which was smaller than the uneducated. Thus, the educated were less likely to be vulnerable in terms of worse economic condition relative to the non-educated.

The formally educated individual most at times are able to project into the future what state of the economy will be. This enables them to take precautionary measures against such future economic turbulence. For example, they are able to predict the investment climatic conditions of the economy, real interest rate, inflation, volatility of exchange rate and other related macroeconomic issues. With these anticipations, they position themselves well to mitigate these negative economic outcomes. The uneducated on other hand, find it difficult to read numbers and let alone to understand the figures and general economic environment. Thus, they are unable to mitigate against negative outcomes in the future. Hence, making them looking more vulnerable to changes in economic conditions.

Majority $(40.3 \%)$ of the respondents with basic education indicated that their economic condition was worse compared with the previous year while 5.2\% indicated that their economic condition was much worse. About 31\%, 22\% and $1 \%$ indicated that their economic conditions were the same, better and much better, respectively. On the whole the likelihood of a respondent with basic education being vulnerable in terms of worse economic condition was $45.5 \%$. This is higher than those with no formal education.

This finding is not surprising since basic education accords the individual with little knowledge with respect to financial literacy and economic related issues. Besides, they spent nine years in basic education, foregoing incomes that could have been earned to protect them against economic misfortunes. The respondents with secondary education $41.2 \%$ reported having worse economic condition. About $23.8 \%$ of the respondent indicated that their economic condition was the same and the same percentage also indicated that their economic condition was better. Only one respondent (1.2\%) indicated that his/ her economic condition was much better while $10 \%$ of the respondents indicated that their economic condition was much worse. On the whole, majority of the respondents with secondary education reported worse economic conditions.

Comparatively, the respondents with secondary education were more likely to experience worse economic condition relative to those with no education. Even though individuals with secondary education have fundamental knowledge on financial literacy and economic related issues and techniques required to take precautionary measures against negative economic outcomes or misfortunes, lack of employment might not position them to forestall economic misfortunes.

As it is evident in the country there is massive youth unemployment and majority of them are likely to be secondary school leavers. Sometimes they feel embarrassed to join the informal sector for livelihood waiting to be employed in the formal sector, thus worsening their economic conditions when there are negative economic outcomes. Further, in the present study $34.3 \%$ of the respondents with tertiary education indicated that their economic conditions were the same. About 32.6\% also indicated that their economic condition is better compared with previous year. A few of the respondents (2.2\%) indicated that their economic condition is much worse. About $27.8 \%$ and $3 \%$ of the respondents indicated their economic conditions are worse and much better, respectively. The probability that the respondents with tertiary education will be vulnerable with respect to worse economic condition is $30 \%$. Comparatively, the respondents with tertiary education are less likely to be vulnerable relative to those with no education. Individuals with tertiary education have greater chances to be employed in the formal sector thus earning formal wages and salaries.

All other things being equal, their level of financial literacy is relatively advanced. They have access to better information on investment market, macroeconomic indicators, and the ability to understand these indicators and on top of it take decisions based on these figures. Besides, their employers protect them against negative economic outcomes such as high inflation, volatile exchange rate, and to mention a few. Through various unions they agitate for salary increment whenever there are high levels of inflation, thus protecting their purchasing power and purse. The result of the present study supports GSS (2014) report which suggests that a strong negative relationship exists between poverty and educational level, such that the more educated the household head is the less likely they are to be poor.

\subsection{Financial Dependency and Formal Education}

The results show that there was a relationship between the degree of financial dependency and formal education, $\chi^{2}(676,3)=12.095, p=007$. Respondents who were not educated representing 38 percent were dependent when it comes to finances and 11.6 percent indicated that they are highly financial independent. About 12.4 percent and 37.5 percent of the respondents indicated that their finances are highly dependent and independent respectively. Thus, the probability that the respondents with no education to be vulnerable in the context of financial dependency is 51 percent (12.4\% plus 38.6\%). The results are presented Table 5.6. 


\begin{tabular}{|c|c|c|c|c|c|}
\hline Educational Status & \multicolumn{5}{|c|}{ Degree of Financial Dependency } \\
\hline & Highly Dependent & Dependent & Independent & Highly Independent & Total \\
\hline Non-educated & 32 & $10038.6 \%$ & 97 & 30 & 259 \\
& $12.4 \%$ & & $37.5 \%$ & $11.6 \%$ & $100 \%$ \\
\hline Educated & 39 & 140 & 209 & 29 & 417 \\
& $9.4 \%$ & $33.6 \%$ & $50.1 \%$ & $7 \%$ & $100 \%$ \\
\hline Chi-square Test & \multicolumn{4}{|c|}{$\chi^{2}=12.095, \quad \mathrm{p}=.007$} \\
\hline
\end{tabular}

Table 8: Financial Dependency and Formal Education

$*$ Missing Value $=24$

Source: Author's Construction Based on Data

Obtained from the Field of Study, 2016

The results further revealed that the majority of the respondents with formal education indicated that they were financially independent (Table 5.7). This represents 50.1 percent of the total respondents who were educated. The minority of the respondents representing 7 percent indicated that they are highly financially independent. About 9.4 percent and 33.6 percent reported that they were highly financially dependent and financially dependent respectively.

Thus, the respondents with no education are more likely to be vulnerable relative to those who are educated in terms of financial dependency. About $12.4 \%$ and $37.5 \%$ of the respondents indicated that their finances are highly dependent and independent respectively. Thus, the probability that a respondent with no education would be vulnerable in the context of financial dependency was $51 \%$. The results further revealed that the majority of the respondents with formal education indicated that they were financially independent. A minority (7\%) of the respondents indicated that they are highly financially independent. About $9.4 \%$ and $33.6 \%$ reported that they are highly financially dependent and financial independent, respectively. Thus, the respondents with no education were more likely to be vulnerable relative those who are educated in terms of financial dependency. Individuals with no formal education most of the times do not diversify their sources of income, thus relying on one source of income. Most of them have poor attitude towards savings. This makes them more financially dependent on their jobs. The educated, on the other hand, have good habit of savings; diversify their sources of income, therefore do not rely on one source of income for livelihood.

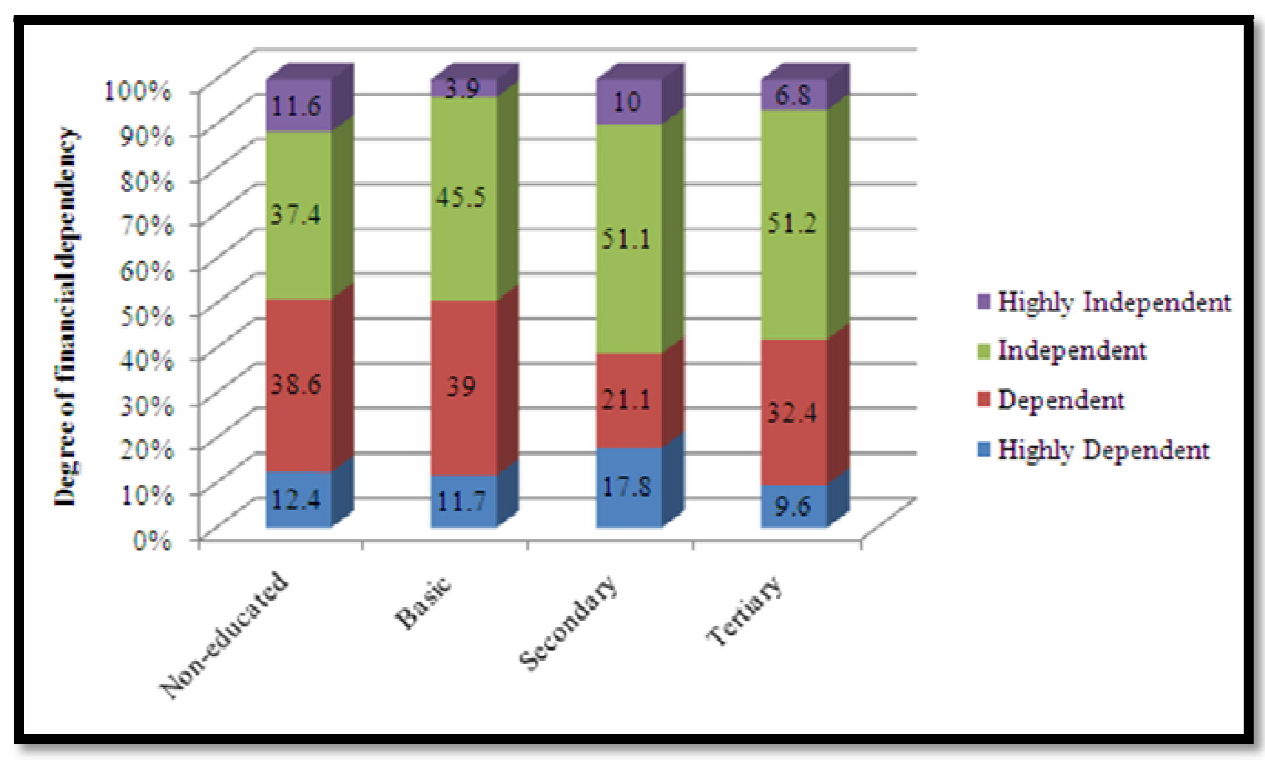

Figure 2: Financial Dependency and Formal Education

The chi-square test indicates significant relationship between financial dependency and levels of formal education, $\chi^{2}(676,6)=16.804, p=.052$ at $10 \%$ level. The results revealed that nearly $46 \%$ of the respondents with basic formal education were financially independent. The results revealed that majority of the respondents (45.5\%) with basic formal education are financially independent. Again, about $4 \%$ of them indicated that they are highly financially independent which represents minority of the group. About $11.7 \%$ and $39 \%$ indicated that they were highly financially dependent and financially dependent respectively. About $51 \%$ of the respondents with secondary education indicated that they were financially independent while $10 \%$ said they were highly financially dependent.

The minority of the group representing $6.7 \%$ indicates that they were highly dependent while $32.2 \%$ percent purport to be financially dependent. Thus, the probability of the respondents with secondary education being vulnerable in terms of financial dependency $38.9 \%$. Comparatively, this is lower than the respondents with no formal education. The results further revealed majority of the respondents with tertiary education were financially independent representing $51.2 \%$. About $10 \%, 32.4 \%$ and $6.8 \%$ indicated that they were highly dependent, dependent and highly independent respectively. The probability that a respondent with tertiary education would be vulnerable in terms of financial dependency was $42.2 \%$. 
Comparatively, respondents with tertiary education were less likely to be vulnerable in terms of financial dependency relative to those with no formal education. The results revealed that higher levels of education such as secondary and tertiary makes the individual less vulnerable in terms of financial dependency. This is in line with (World Bank, 2016) reports which states that lack of education leads to extreme vulnerability to ill health, economic dislocation, natural disasters. Uneducated people are often exposed to ill treatment by institutions of the state and society and are powerless to influence key decisions affecting their lives. On the other hand, the educated are often better placed in society as they are able to influence decision making and diversify their source of income, thus making them less vulnerable to the powers of state and society both in political and economic terms.

\section{Relationship between Job Security and Formal Education}

The study further investigated the relationship between respondents' state of finances when there is a shock and change of educational status of the respondents. The Chi-square test revealed that there was a significant relationship between educational status and job security, $\chi^{2}(676,3)=12.095, p=.007$. The Chi-square test revealed that there is significant relationship between educational status and job security. Thirty eight of the respondents who are uneducated indicated that they are very insecure representing $15 \%$ of the total respondents for the uneducated. Majority of the respondents (61\%) indicated that they were insecure. About 205 and $12 \%$ of uneducated group indicated that they were secure and very secure, respectively. Hence, the probability that a respondents who was uneducated being vulnerable in terms of job insecurity was $76 \%$. Majority of the respondents (50.1\%) with education on other hand indicated that they were secure. About $9 \%, 34 \%$ and $7 \%$ indicated that they were very secure, insecure and very secure, respectively.

Thus, one can conclude that the probability of a respondent with education being vulnerable in terms of job security was $43 \%$. This is intuitively plausible as majority of the uneducated in the rural communities are farmers thus their jobs being tied to harsh weather conditions and lack of rainfall for most part of the year. On the contrary most of the educated individuals are found in the formal sector employment. They were secure because unions protect their interest and moreover the level of financial literacy makes them diversify their sources of income against future eventualities. The results are presented in Table 5.8.

\begin{tabular}{|c|c|c|c|c|c|}
\hline Educational Status & \multicolumn{5}{|c|}{ Degree of Financial Dependency } \\
\hline & Very Insecure & Insecure & Secure & Very Secure & Total \\
\hline uneducated & $3815.0 \%$ & $15561.0 \%$ & $50 \quad 19.7 \%$ & $30 \quad 11.6 \%$ & $259 \quad 100 \%$ \\
\hline Educated & $399.4 \%$ & $14033.6 \%$ & $20950.1 \%$ & $7.0 \%$ & $100 \%$ \\
\hline Chi-square Test & & & $=12.095, \mathrm{p}=.0$ & & \\
\hline
\end{tabular}

Source: Author's Construct Based on Data Obtained from the Field of Study, 2016

On the various levels of education, the results revealed that 10 percent of the respondents with basic education are very insecure. Majority of them also indicated they were insecure. About 31 percent and 4 percent of the respondents with basic education indicated that they were secure and very secured respectively. The likelihood that a respondent with basic education will be insecure is 67.5 percent. This is relatively smaller than the non-educated. The results are presented in figure 5.4.

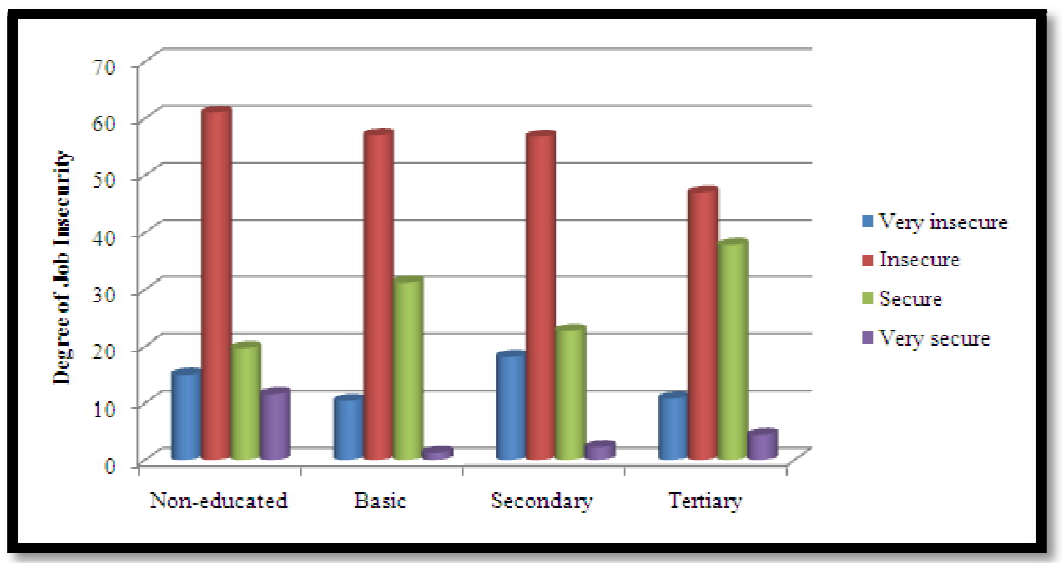

Figure 3: Relationship between Job Security and Levels of Education

The results also revealed $10 \%$ of the respondents with basic education indicated that they were very insecure. Majority (67.5) of them also indicated they are insecure. About 31\% and 1\% of the respondents with basic education indicated that they were secure and very secure respectively. The likelihood that a respondent with basic education would be insecure was $67.5 \%$. The results further revealed that respondents with secondary education who indicated that they were insecure was $18.2 \%$ while $56.8 \%$ indicated that they were secure. About $23 \%$ and $2 \%$ indicated that they were secure and much secured respectively. 
Thus, the likelihood for a respondent with basic education being insecure was $75 \%$. Comparatively this is lower than those with no education. Finally, about $10.8 \%$ of the respondents indicated that they were very insecure while $47 \%$ indicated that they were insecure. About 38\% and 7\% of them indicated that they were secure and very secure respectively. Therefore, those who were likely to be vulnerable with tertiary education in terms job insecurity were $57.8 \%$. Relatively, this is smaller than those with no formal educational background.

All the three levels of formal education persistently performed better than the uneducated, though the figures were not encouraging with respect to majority of the respondents who were insecure. The finding suggests that majority of them did not take entrepreneurial initiative to establish businesses that would mitigate the risk of losing in the formal sector.In addition, lower educational attainment not only leads to lower, but also less secure employment and more frequent and longer spells of unemployment and thus generates the dynamics of detachment from the labour market that can lead to long-term social exclusion (Wilson, 1987; Gottschalk, et al., 1994; Mincy, 1994; Walker, 1997).

Apart from poor educational attainment, poor educational achievement, as measured by literacy and numeracy tests, has an even stronger impact on unemployment rates. OECD (1997) has shown that poor literacy and numeracy leads to higher unemployment rates, longer spells of unemployment, and greater risks of permanent detachment from the labour force. The dominant mode of analysis has focused on the concept of human capital. From this perspective education or schooling increases productivity as it equips individuals' with skills and knowledge.

As productivity is reflected in earnings and rates of labour market participation, education offers an important means of social mobility, particularly for the poor. Widespread changes in the economy such as the emergence of highlevel service sector jobs have opened up important opportunities, to those with the necessary levels of education. The government certainly adopts this perspective. This is in line with Bening's (1990) assertion that, accelerating economic growth and poverty reduction depends ultimately on people; the abundance of natural resources and capital investment alone may not necessarily generate economic growth.

The improvement of the level and quality of the human resources is all important and the absence of a system of education capable of producing the men with the right skills and attitudes as a result of the proscription of secondary and technical education impeded progress and frustrated the results expected from investment. As stated earlier on, Bening (1990) supported this view with an example from 1940, where the officer in charge of the Water Supplies Division of the Geological Department of the Gold Coast responsible for sinking wells in the Northern Territories complained of slow progress owing to shortage of European staff. To speed up the work he had to recruit indigenous staff as foremen but this was not possible because their standard of education was too low, yet people from Ashanti and the Colony did not get on well with those of the Protectorate. It can, therefore, be understood that job security depends on human capital formation and human capital formation depends on education and skilled training.

\section{Relationship between Formal Education and Social Exclusion}

This section of the study presents and analyses the relationship between formal education and social exclusion (Table 10).

\begin{tabular}{|c|c|c|c|c|}
\hline \multirow{2}{*}{ Educational Status } & \multicolumn{4}{|c|}{ Social Exclusion } \\
\hline & Yes & No & & \\
\hline Non-Educated & $20.5 \%$ & $79.5 \%$ & 258 & $100 \%$ \\
\hline Basic & $1925.0 \%$ & $5775 \%$ & 76 & $100 \%$ \\
\hline Secondary & $14 \quad 15.2 \%$ & $\begin{array}{ll}78 & 84.8 \%\end{array}$ & 92 & $100 \%$ \\
\hline Tertiary & $13.1 \%$ & $86.9 \%$ & 245 & $100 \%$ \\
\hline Chi-square Test & $\chi^{2}=8.190 \quad p=017$ & & & \\
\hline
\end{tabular}

Table 10: Relationship between Levels of Formal Education and Social Exclusion

$*$ Missing Value $=29$

The results revealed that there was no significant relationship between educational status and the state of social exclusion. In other words there are no differences in the state of social exclusion across educational status of the respondents. Majority of the respondents with no education were not isolated from the society which is about $80 \%$. Only $20.5 \%$ indicated that they were socially excluded from the society. Thus, the probability of a respondent with no education to be isolated from society was $20.5 \%$. With the educated group, majority (84.3\%) of the respondents indicated that they were not socially excluded from the society. Only $15.7 \%$ indicated that they were socially excluded from the society. In the rural community, individuals see themselves as one thus, irrespective of once educational status, they associate with each other, form associations and discuss social issues that border on their lives.

The chi-square test revealed that there was a significant relationship between the levels of education and social isolation, $\chi^{2}(553,3)=8.190, p=.017$ The respondents with basic education who felt isolated from the community were 19 $(25 \%)$. The remaining $75 \%$ of the respondents indicated that they were not isolated from the community. Thus, the likelihood that respondents with basic education being isolated from the community was $25 \%$. Comparatively, this is bigger than the uneducated. The results further revealed that the respondents with secondary education who felt isolated from the community were $14(15.2 \%)$. The majority $(84.8 \%)$ of them indicated that they did not feel isolated from the community. Hence, the probability that a respondent with secondary education would feel isolated from the community was $15.2 \%$. Comparatively, this is smaller than that of the respondents with basic education.

Majority of the respondents with tertiary education indicated that they did not feel isolated from the community while the remaining $13.1 \%$ felt isolated. Thus, the probability that a respondent with tertiary education to be considered 
isolated from the community was $13.1 \%$. The probability of being isolated from the community was relatively smaller than the non-educated. Irrespective of the level of education, the people saw themselves as one, interacted and communicated with each other on the regular basis. According to Klazen there are good reasons to perceive educational achievement or rather, the access to and utilisation of education, training and learning opportunities as a key factor in the process of becoming excluded. Lack of equality in access to good education (from early childhood on) can contribute to or at least increase the chance on becoming excluded, since it highly determines (apart from intelligence and aptitude to learn) the further educational career and with that the working career of a person.

\section{Relationship between Formal Education and Political Exclusion}

The study also examined the relationship between formal education and political exclusion. Table 11 reveals the empirical results.

\begin{tabular}{|c|c|c|c|}
\hline \multirow{2}{*}{ Educational Status } & \multicolumn{3}{|c|}{ Political Exclusion } \\
\cline { 2 - 4 } & Yes & No & Total \\
\hline Non-Educated & 153 & 109 & 262 \\
& $58.4 \%$ & $41.6 \%$ & $100 \%$ \\
\hline Educated & 281 & 141 & 422 \\
& $66.6 \%$ & $33.4 \%$ & $100 \%$ \\
\hline Chi-square Test & \multicolumn{3}{|c|}{$4.676(0.031)$} \\
\hline
\end{tabular}

Table 11: Relationship between Formal Education and Political Exclusion

*Missing Value $=16$

Source: Author's Construction Based on Data Obtained from the Field of Study, 2016

The results revealed that there is a significant relationship between formal education and political exclusion at the 5 percent level of significance. The respondents with no formal education indicated that they have equal opportunity in the participation of governance representing 58.4 percent. The remaining 41.6 percent of the non-educated respondents indicated that they don't have equal opportunity in the participation of governance. The probability that respondents with no formal education will be politically excluded is 41.6 percent. The results further revealed that 281 of the respondents with education indicated that they have equal opportunity in the participation of government representing 66.6 percent. The remaining 141 of the respondents representing 33.4 percent indicated that don't have equal opportunity participation of governance. The probability that a respondents with education will be socially excluded is 33.4 percent. The educated have the confidence and charisma to express their views concerning the governance of the nation. Some even take up position such as assembly men to lobby for the welfare of the people in their locality. The uneducated on other hand find it difficult to express their views, not confident to contest for District Assembly elections, and to mention a few.One of the most consistently documented relationships in the field of political behaviour is the close association between educational attainment and political participation. For more than half a century, researchers have found that more educated citizens are more likely to vote in elections and participate in campaigns (for reviews, see Campbell et al., 1960; Hillygus 2005; Nie et al. 1996; Wolfinger and Rosenstone 1980). For some scholars, the reason for this relationship is clear: education gives citizens the skills and resources needed to participate in politics. For instance, Verba et al. (1995) argue that education not only directly increases levels of participation, but also allows citizens to acquire the civic skills necessary to effectively communicate their concerns to politicians.

\section{Conclusion}

The study examined the effect of formal education on poverty reduction in the district. A total number of 701 respondents were sampled for the study. Binary regression model was employed to estimate the effect of formal education on poverty reduction of the people in the study area. To determine the relationship between formal education and vulnerability as well as the relationship between formal education and social or political exclusion,the study concludes formal education increases the chances of occupying modernized housing structure and also one's ability to meet his or her nutritional requirement. It further concludes that the formally educated individual especially to the higher level of education such as tertiary education insulates the individual from becoming poor. In other words they are less vulnerable in economic sense. However, secondary and basic educated individuals' chances of being trapped in poverty through vulnerability are very high. Moreover, formally educated have greater chance to be part of the social fabric as well as participate in the governance of their locality, the district and nation at large. Thus, formal education consolidates the individual's position as being non-poor entity.

The poor districts and communities should therefore be allowed to access education freely to the secondary level so that they get better chances of improving their livelihood. This will go a long way to reduce the levels of poverty through educational empowerment, human capital formation, skills training and employment opportunities.It is also important that political structures should be amended to be all-encompassing. This will render the non-educated an opportunity to voice out their opinions and also channel their grievances to the authorities. Such a policy is likely to be one of the most effective tool of reducing poverty at the community and district levels.

\section{Competing Interest}

Authors declare no competing interest as far as this paper is concerned. 


\section{References}

i. Bramley, G. and Karley, K.N. (2005). Home-Ownership, Poverty and Educational

ii. Achievement: Individual, School and Neighbourhood Effects. CRSIS Research Report,

iii. www.crsis.hw.ac.uk.

iv. Creswell, J. W. (2010), "Research design: Qualitative, quantitative, and mixed methods approach" (3rd ed.), Thousand Oaks, CA: Sage Publications.

v. Colclough, C. Al-Samarrai S., Rose, P. and Tembon M. (2003). Achieving Schooling for All in Africa: Costs, Commitment and Gender:Aldershot: Ashgate Press.

vi. Ghana Statistical Service (2014). Ghana Living Standards Survey: Report of the Sixth Round. Accra: GSS

vii. Ghana Statistical Service (2012). 2010 Population and Housing Census: Summary Reports of Final Results, Accra: GSS

viii. Ghana Statistical Service (2000). Poverty trends in Ghana in the 1990s, Accra: GSS

ix. Hillygus, D.S (2005). The missing link: Exploring the relationship between higher education and political behavior. Political Behavior, 27(1), 25-47.

x. Hunt, N., Tyrrell, S. (2001). Stratified Sampling. Webpage at Coventry University

xi. Jeffery, R. and Basu, M.A. (1996). Girls' Schooling, Women's Autonomy and Fertility

xii. Change in South Asia: New Delhi: Sage Publications.

xiii. Krejcie, R.V., \& Morgan, D.W., (1970). Determining Sample Size for Research Activities. Educational and Psychological Measurement. Small-Sample Techniques (1960). The NEA Research Bulletin, Vol. 38.

xiv. Masood Sarwar Awan, Nouman Malik, Haroon Sarwar, Muhammed Waqas (2011). Impact of Education on Poverty Reduction: University of Islamabad, Pakistan.

xv. Stake, R. E. (1995). The art of case study research. London: Sage

xvi. UNICEF (2000). Poverty Reduction Begins with Children, New York.

xvii. UNESCO (2007). “Education for All: Global Monitoring Report 2007”, www.unesco.org

xviii. UNESCO-PROAP (1998). "Basic Education for Empowerment of the Poor”: Bangkok.

xix. World Bank (2016). Poverty and Shared Prosperity: Taking on Inequality. Washington DC: World Bank.

xx. Tilak, J. B. G. (2005). Post-Elementary education, poverty and development in India. Centre of African Studies, University of Edinburgh.

xxi. Verba, S., Schlozman, K.L. and Brady, H. (1995). Voice and equality: Civic voluntarism in American politics. Cambridge: Harvard University Press

xxii. Wolfinger, R.E. and Rosenstone, S.J. (1980). Who votes? New Haven: Yale University

xxiii. Yin, R. K. (2009). Case Study Research, Design and Method. London: Sage Publications Ltd. 